Original Research Paper

\title{
Management of Beef Cattle Production in Malaysia: A Step Forward to Sustainability
}

\author{
${ }^{1}$ Ibragimov Abdulla, ${ }^{1}$ Fatimah Mohamed Arshad, ${ }^{2}$ B.K. Bala, \\ ${ }^{1}$ N.L. Bach and ${ }^{1}$ Sahra Mohammadi \\ ${ }^{1}$ Institute of Agricultural and Food Policy Studies, \\ Universiti Putra Malaysia, 43400 UPM Serdang, Selangor, Malaysia \\ ${ }^{2}$ Department of Agro Product Processing Technology, \\ Jessore University of Science and Technology, Jessore, Bangladesh
}

\author{
Article history \\ Received: 16-07-2016 \\ Revised: 11-09-2016 \\ Accepted: 15-09-2016 \\ Corresponding Author: \\ Ibragimov Abdulla \\ Institute of Agricultural and \\ Food Policy Studies, Universiti \\ Putra Malaysia, Selangor, \\ Malaysia \\ Email: upmikdpm@gmail.com
}

\begin{abstract}
The beef cattle industry recorded progressive growth in the last two decades. Despite this growth, suppliers are having difficulty to meet the domestic demand for beef. Continued strong growth of beef cattle production capacity depends on supplier profitability, which in turn will be influenced by primarily on availability of feedstuffs that constitutes a large proportion of the cost of production. The policy design and management of beef cattle production systems in Malaysia is challenging since imported beef is much more profitable. To this end, the research has applied systems approach that can be used to study and understand the behavior of a complex system over time which is characterized by interdependence, mutual interaction, information feedback and circular causality. The results indicate that low beef price and feed cost ratio would worsen beef cattle production. However, development of grazing and fodder area and genetic improvement boost the beef cattle production significantly by 2020 . The results of this research support the idea that the best policies to obtain the targeted self-sufficiency level is through importation of animal for breeding, minimized rate of beef cattle mortality, increased fertility and the conduct of training in feed efficiency management.
\end{abstract}

Keywords: Beef Cattle Production, Management Policies, Malaysia, System Dynamics

\section{Introduction}

The ruminant sector plays a significant role in producing useful animal protein food for the population (Kusriatmi et al., 2014) and raw materials to the meat processing industry in Malaysia. The ruminant sector comprises beef cattle, buffalo, goat and sheep subsectors. In 2010, the beef supply alone contributed $0.011 \%$ to the GDP and around RM 62 million to the value added in agriculture (Mohamed, 2007). The beef industry recorded progressive growth in the last two decades. Despite this growth, suppliers are having difficulty to meet the domestic demand for beef. The Malaysian beef cattle production capacity has enhanced by factors such as breeding and import of beef cattle.

Currently, almost $90 \%$ of the ruminant population is still operated by small farm holders. Small farm holders do not grow pastures for animals in contrast to the commercial and government farms where there are wellestablished infrastructures and pastures (Mohamed et al.,
2013). Particular regulations will be put into effect by the government to increase the beef cattle production and reduce imports of beef, mutton and milk. Such as in eleventh Malaysia plan, primary focus will be given on intensifying research in genetic improvement, ameliorating existing breeding techniques, ensuring adequate supply of animal feed, improving dairy facilities and establishing small-scale farms. These strategies are expected to enhance the self-sufficiency of beef from $27 \%$ in 2014 to $50 \%$ in 2020 .

Continued strong growth of beef cattle production capacity depends on supplier profitability (Hirooka, 2010), which in turn will be influenced by primarily on availability of feedstuffs that constitutes a large proportion of the cost of production (Loh, 2002), lack of number of quality breeding stocks, unorganized breeding system (Johari and Jasmi, 2009), technologies and government regulations. The ruminant feed is often provided with locally available feedstuffs, for example 
PKC (Palm Kernel Cake), palm oil sludge, oil palm frond and soy waste (Hassan et al., 1994). Supply of domestic raw materials consists roughly 30 percent of the total feedstuff in the country. The feedstuff industry is dependent on imported raw materials which valued at RM10 billion a year. On the other hand, the price of feed ingredients is showing unstable performance in the international market. Chiew (2001) argued that production of feed was not realizable locally due to shortage of arable land and poor returns.

The Kedah-Kelantan (KK) cattle account for roughly $85 \%$ of the total number of beef cattle in Malaysia (DVS, 2014). The KK beef cattle is a small sized cattle breed vary in mature weight from about 300 to $312 \mathrm{~kg}$ in male and from 229 to $240 \mathrm{~kg}$ in female. They are well adapted to the Malaysian environment and are highly tolerant to parasites. The KK cattle are known to have high fertility and calving rate. In spite of the high calving rate, the productivity of $\mathrm{KK}$ cattle is still showing low performance. This is mainly attributed to its sluggish growth rate, which is reflected on low profitability in commercial production. The mean growth rate of $\mathrm{KK}$ calves indicated $0.36 \mathrm{~kg} /$ day. However, $\mathrm{KK}$ cattle is likely to gain weight up to $0.6 \mathrm{~kg} /$ day in feedlot method (Johari and Jasmi, 2009).

In the ruminant sector, majority of breeder animals are brought from Australia (Bindon and Jones, 2001) and New Zealand (Morris and Kenyon, 2014). Growing demand from other breed importing countries and short supply of quality breeder animals have led in higher import costs. Furthermore, the imported breeds are liable to suffer from diseases and hard to adapt to the local condition. Cattle production is a challenge given the insufficiency of land and grazing areas for cattle rearing as well as high feed resource costs.

Cattle nutrition and feeding practices in Malaysia mainly aims on fattening of animals for slaughter and using agriculture waste product as feed resource. Few researches have been conducted to assess the profitability of feeding practices in large size farming (Mohamed et al., 2013). Although Malaysia has sufficient land area, it does not establish large scale pasture area to graze cattle. Cash crops such as oil palm and rubber occupies most of the developed agriculture lands in the country. Palm oil plantation in Malaysia covers 5.48 million hectares of land and integrated cattle grazing in oil palm plantation was estimated to be successful (Tohiran et al., 2008). The oil palm cattle integration can be a substitute to field pasture for grazing (Mohamed et al., 2013). Pasture area increase, strongly associated with the expansion of the agricultural frontier, is the major factor explaining the beef production growth (Martha et al., 2012).

Considering the above notions of beef cattle production, there is a need to seek a policy to enhance beef production efficiency to prevent Malaysian reliance on imported meat and cattle. The realization of this policy will not only accomplish the target of the beef cattle sector to meet the domestic demand, but it could also be a step forward to avoid the food security issues. The poor performance of the beef cattle production along with strong competition for factors from agricultural activities particularly oil palm on the one hand and cheaper prices of imported beef on the another hand, make beef cattle production disadvantageous to operate locally. Therefore, this study makes a major contribution to research on development of a model for beef policy analysis via systems approach.

\section{Materials and Methods}

The beef cattle production level in Malaysia has been increasing slowly over the last few decades. Although attempts have been made to enhance beef cattle production, it is still insufficient to meet the local demand for beef and beef products. The policy design and management of beef cattle production systems in Malaysia is challenging since imported beef is much more profitable. The management of beef cattle production systems in the country is a complex, dynamic and versatile depending not only on incentives but also on economic and social factors. Having adopted a computer simulation model, one can carry out different tests in solving the beef cattle production issues. Simulation models clearly are of great value in decisionmaking and to understand the dynamics of complex systems. Therefore, in this study the system dynamics approach is used for analyzing a beef cattle production.

System dynamics is a methodology that can be used to study and understand the behavior of a complex system over time which is characterized by interdependence, mutual interaction, information feedback and circular causality (Sterman, 2000; Abdulla and Arshad, 2015). It deals with internal feedback loops and time delays that affect the behavior of the entire system (Rosen et al., 1994). It uses structural approach which utilizes system thinking technique. Using this approach, the reality or actual scenario will be structured in the model. In the social phenomena structure, there exists an interaction between physical structure and decision making structure. The physical structure is formed by the accumulation of stock and flow of people, goods, energy and materials. The decision making structure is formed by the accumulation of stock and flow used by the factors (human) in the system that describes the rules of decision making process.

\section{Causal Loop Diagrams}

The causal loop diagram of beef cattle production system in Malaysia is given in Fig. 1. Causal loop diagrams are used to indicate the main feedback loops of the systems and hypothesized to generate the behavior in a specific time horizon. 


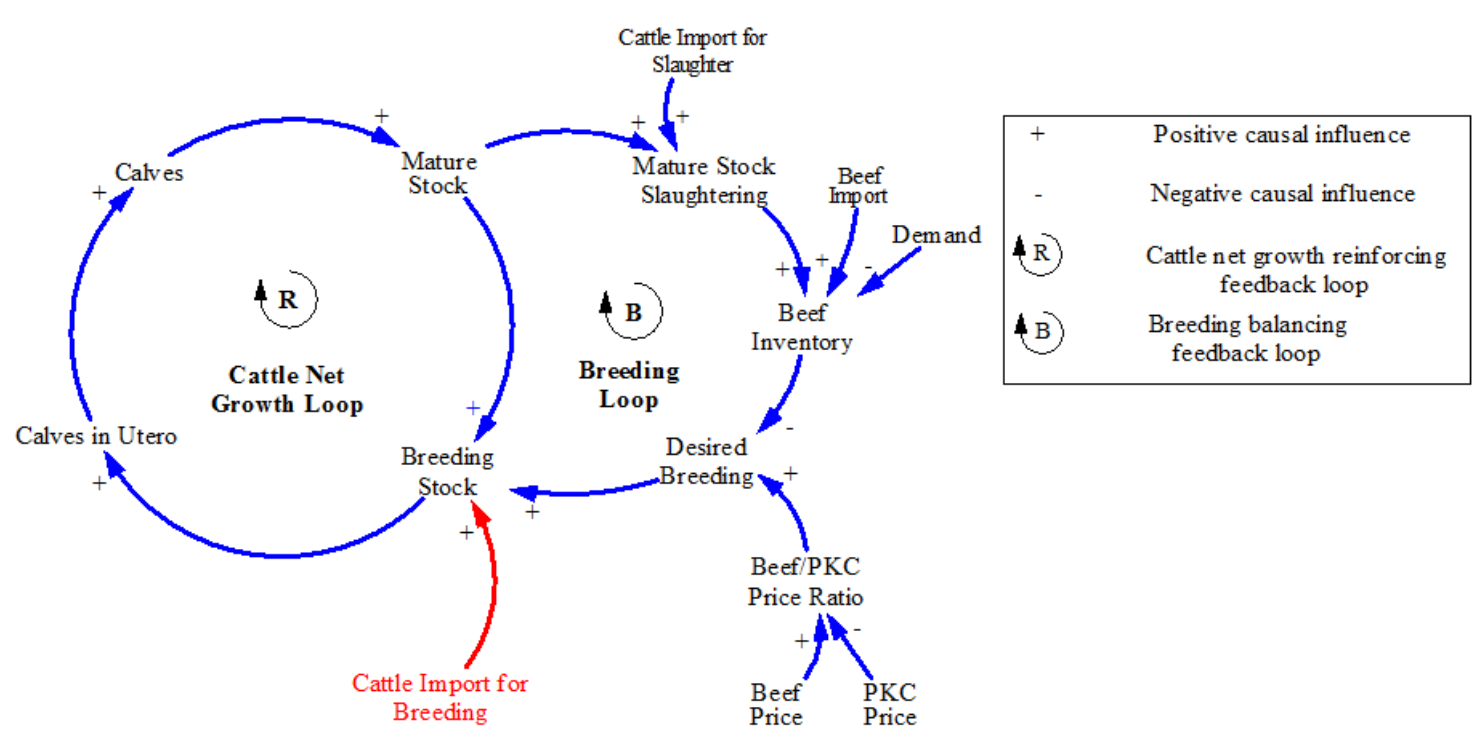

Fig. 1. Causal loop diagram of beef cattle production system in Malaysia

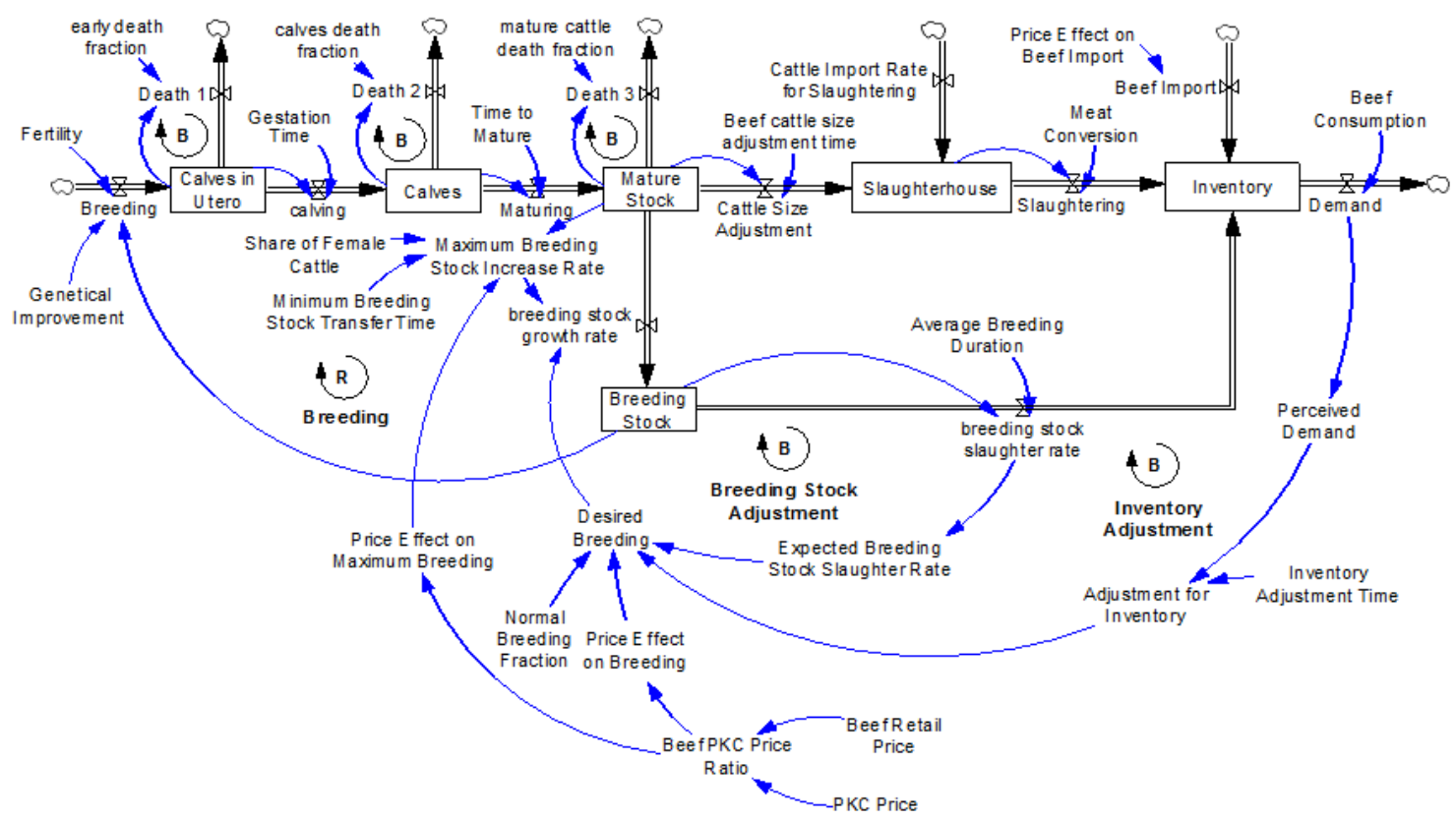

Fig. 2. Stock and flow diagram of beef cattle production system in Malaysia

A feedback loop is a closed chain of causal connections from a stock, through a set of decisions or rules or physical laws or actions that are dependent on the level of the stock and back again through a flow to change the stock (Meadows, 1979). There are two types of feedback that can occur in a system. The positive feedback represents the growth pattern while the negative feedback is goal seeking (Ibragimov, 2014; Arshad, 2015). The combination of those feedbacks will produce various behaviors that present the real system. There are 2 principal feedbackloops in beef cattle production system in Malaysia. Of which one is reinforcing and another is goal seeking.
The balancing loop $\mathrm{B}$ and reinforcing loop $\mathrm{R}$ represent the breeding loop and cattle net growth loop respectively. Balancing loop B includes mature stock, mature stock slaughtering, beef inventory, desired breeding, breeding stock, calves in utero and calves whereas $\mathrm{R}$ includes breeding stock, calves in utero, calves and mature stock. The relationships between the variables follow the principles of an economic theory. As the price of beef increases (decreases) producers expected profitability will increase (decrease), thus farmers desired breeding tend to increase (reduce). 


\section{Stock-Flow Model}

Dynamic systems comprise interrelated feedback relationships and the feedback relationships generate dynamic trend of the systems. The stock is a state variable and it characterizes the state of the system at any point in time $t$. The flow demonstrates how the stock adjusts with time. Figure 2 shows the stock-flow diagram of the beef cattle production system in Malaysia. The relationships given in the flow diagram are provided in terms of mathematical equations which are solved numerically to reproduce the dynamic behavior (Forrester, 1968). The algebraic equations that explain stock (stock (t)) and flow systems are given by integral equations:

$\operatorname{stock}(t)=\operatorname{stock}(t-1)+$ inflow $\times \Delta t-$ outflow $\times \Delta t$

The stock ( $\mathrm{t}$ ) is a state variable at any moment $\mathrm{t}$ and it is depicted by a rectangle. The flow presents how the stock adjusts with time and it is portrayed by valve icon. The arrow towards the stock denotes inflow and the arrow outwards denotes outflow. The lines with arrow are influence lines and the direction indicates the direction of information flow. In Fig. 2, calve in utero is a stock variable and breeding rate is inflow into the stock-calves in utero.

There are six stocks in the beef cattle production model (Fig. 2) which are calves in utero (CIU), calves (C), mature stock (MS), Breeding Stock (BS), Slaughterhouse (S) and inventory (I). Breeding rate (B) augments the CIU and is the function of the BS and fertility. The relationship is captured in equation:

$$
\Delta B=B S(t) \times \text { Fertility }(t)
$$

The KK cattle and cattle of similar origin usually have an average 254 days of gestation period (Jack and Ancharlie, 2002) and in the model calves in utero is diminished by calving rate (CR) which is calves in utero divided by gestation time:

$$
d(C I U) / d t=B(t)-C R(t)
$$

$$
\Delta C=C I U(t) / \text { Gestation Time }
$$

The stock variable, calves is augmented by the CR and is diminished by the Maturing Rate (MR):

$d(C) / d t=M R(t)-C R(t)$

$\triangle M R=C /$ Time to Mature
The stock variable, MS is increased by the MR, however decreased by the Cattle Size Adjustment (CSA) and Breeding Stock Growth Rate (BSGR) (Beckett and Oltjen, 1993). This is shown in equation:

$d(M S) / d t=M R(t)-C S A(t)-B S G R(t)$

The CSA and cattle import rate for slaughtering (CIRS) augments the $\mathrm{S}$ and is the result of the MS divided by the beef cattle size adjustment time:

$\triangle C S A=M S(t) /$ Beef cattle size adjustment time

The BSGR is calculated as the Maximum Breeding Stock Increase Rate (MBSIR) plus desired breeding:

$\triangle B S G R=\operatorname{MBSIR}(t)+$ Desired Breeding $(t)$

The desired breeding determines the BS movements. The desired breeding is estimated multiplying the normal breeding by the effect of the beef price and feed cost ratio. $\mathrm{PKC}$ prices play an important role since feed is one of the largest and most flexible uses of PKC. Normal formula in Malaysia is mainly based on palm oil one which most readily available is PKC. Beef PKC price is the ratio of the price of a beef to the price of a $\mathrm{kg}$ of PKC and it is the "exchange rate" of a beef in terms of $\mathrm{kg}$ of $\mathrm{PKC}$. Beef PKC price ratio is expressed as:

Beef PKC Price Ratio = Beef Retail Price/PKC Price

The change in the desired breeding is the result of farmer upward (downward) adjustments as a response to profitability, by the increase (decline) of breeding stock when conditions are beneficial (unfavorable).

A set of equations was developed to describe beef cattle production system in Malaysia and was solved numerically using Runge Kutta fourth order method using VENSIM software.

\section{Results}

\section{Model Validation}

Initial values and the parameters were drawn from the primary and secondary data collected from different sources and these are depicted in Table 1.

Ranges of tests were conducted to build up confidence in the model. Tests of validation, sensitivity analysis and policy analysis are considered principal tests for robustness in system dynamics models. The validation procedures such as boundary adequacy check, dimensional consistency check, parameter check, extreme conditions, behaviour reproduction and behaviour sensitivity check were considered to establish confidence in the model. 


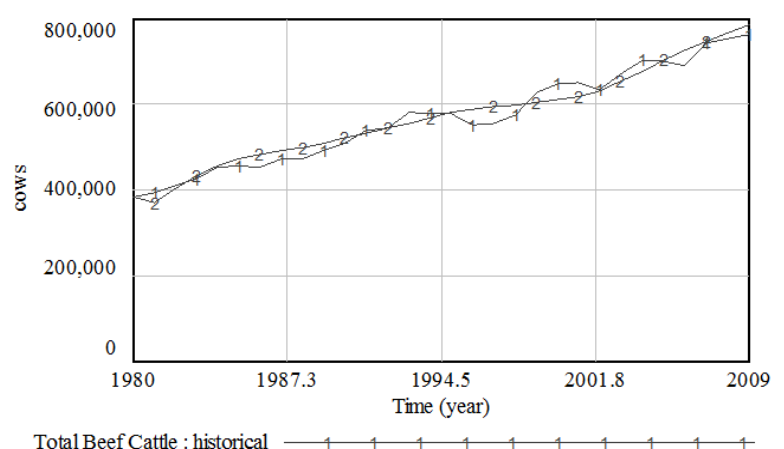

Total Beef Cattle : simulation

Fig. 3. Simulated and historical data of total beef cattle production in Malaysia in 1980-2009

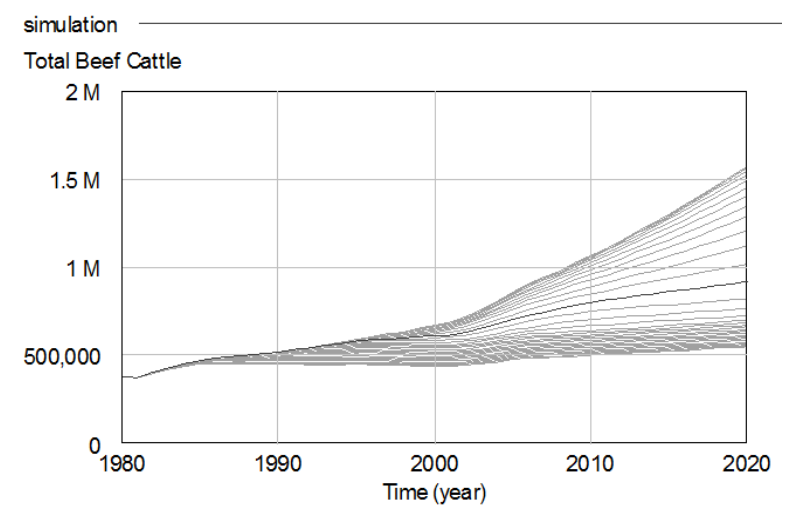

Fig. 4. Sensitivity of beef cattle production to feed price (0.4 to 1.6)

Table 1. Values and parameters for initial simulation

\begin{tabular}{lll}
\hline Name of variable and parameter & Unit & Value \\
\hline Calves in Utero & calves & 2000 \\
Fertility & calves/cow/year & 0.6 \\
Calves & calves & 52,500 \\
Gestation Time & year & 0.7 \\
Mature Stock & cows & 250,000 \\
Breeding Stock & cows & 5,000 \\
Beef Cattle Size Adjustment & year & 2 \\
Inventory & meat & 20,000 \\
Death Fraction & dmnl & 0.007 \\
Meat Conversion & dmnl & 0.2 \\
\hline
\end{tabular}

The simulation model and the actual system should be compared to make sure the model does not contradict the dynamic behaviour of the real system. At this stage, the validity of the model in terms of structure and behaviour needs to be evaluated (Sterman, 2000). If there is no significant difference between simulated and actual behaviour in the reference mode, then the model can be accepted as a valid representation of the system. In the behaviour validity tests, model trend pattern is critical rather than point prediction (Barlas, 1994).

Figure 3 shows the comparison between the historical and simulated behavior of beef cattle production in
Malaysia in 1980-2009. The simulated beef cattle production model agrees adequately with reference behavior and the model is reliable. The verified model was used for business as usual scenario and policy evaluation.

\section{Sensitivity Analysis}

Since the parameters and variables of a system dynamics models are subject to uncertainty, it is essential to conduct a sensitivity analysis for reliability of the results and testing the validity of the model behavior for the changes in parameter and variable values. The price effect is one of the most significant variables affecting the model behavior - i.e., price effect is a function of beef price and feed price. Behavior sensitivity analysis of total beef cattle number to beef and feed prices was conducted and Fig. 4 illustrates the changes in beef cattle number for price for changes of 0.4 to 1.6. The beef cattle production changes from decrease to increase in values for the changes in the feed price from 0.4 to 1.6 and this agree with real world situation. Best and worst case scenarios were defined in this analysis. In the best (worst) case scenario the value of price was set and relationships to the values most (least) favorable to the policies we wanted to test. The worst case scenario to address the beef cattle production might assume relatively high feed price and low beef price. The best case scenario might assume high beef price and low feed cost. Fig. 4 compares these scenarios to the base case.

\section{Discussion}

\section{Policy Analysis}

Policy issues addressed are (1) how palm oil cattle integration and (2) genetic improvement affect beef production in Malaysia. This is done for three cases: (i) effect of palm oil cattle integration, (ii) effect of genetic improvement and (iii) effect of simultaneous change of palm oil cattle integration and genetic improvement. Simulated total beef cattle number for different level of genetic improvement is in Fig. 5 and the adjustments in genetic improvement are made for changes of 0 to $100 \%$.

The number of cattle changes gradually from $0.4 \mathrm{M}$ in 1980 to 1.7 in 2000 and dramatic growth occurs from 1.7 in 2000 to $4.5 \mathrm{M}$ in 2020 for the changes in the genetic improvement of $100 \%$ and this confirms real world condition. Schultz (1974) insisted three types of high pay-off investments for agricultural development: (i) location specific knowledge, (ii) new technological inputs and (iii) schooling and extension education.

For oil palm cattle integration in Malaysia investments in technology for genetic improvement and training and extension services through farmer field schools are needed in order to make the knowledge available to produce more beef output from the same resources. 


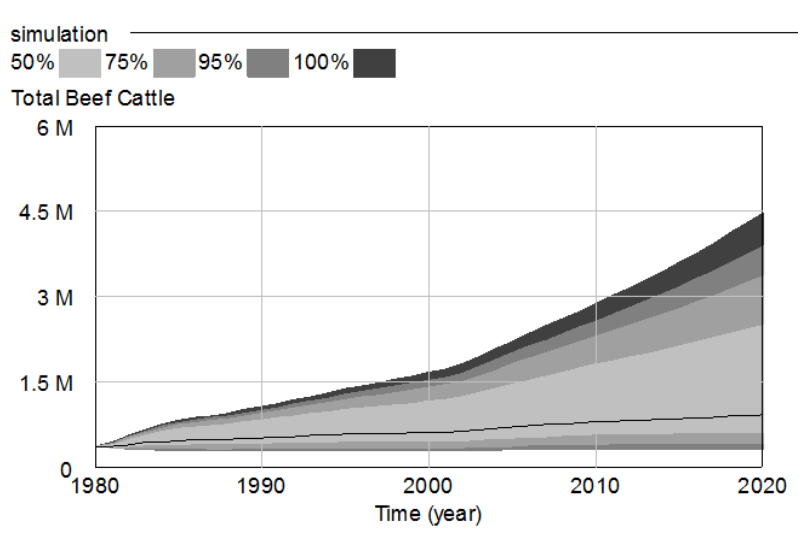

Fig. 5. Sensitivity of total beef cattle to genetic improvement $(0$ to $100 \%)$

Even though Malaysia has commenced to improve the beef cattle industry almost four decades ago, the dismal performance seen today indicates the lack of focus to enhance the industry. Livestock breeding system is poorly developed in Malaysia. Insufficient number of breedable cows largely limits the growth of the industry in Malaysia. This is relevant both for dairy and beef cattle. Improvement of herd fertility in cows and restriction of fertile cows from slaughtering may contribute largely in the increment of their number (Jamaludin, 2014).

Most of the agriculture lands in the country are for industrial crops such as oil palm and rubber. Oil palm area in Malaysia occupies almost 5 million hectares of land and integrated beef cattle grazing in oil palm plantation was estimated to be profitable (Tohiran et al., 2008). The oil palm cattle integrative method can be a substitute to field pasture for grazing. Slade (2014) argued that there are biological and financial advantages to beef cattle grazing under oil palm. Moreover, grazing beef cattle under oil palm has the potential to provide economic benefits through supplying an alternative product, lowering the need for costly weed management and enriching the soil.

Similarly Sanderson et al. (2013) found that the objectives for pastures controlled for organic production of cattle are to form soil structure and fertility, control pests ecologically, protect and encourage plant and animal biodiversity and enhance forage quality and production. Since organic and pasture-based cattle producers must rely on pastures controlled without chemical inputs for milk production or live weight gain. This view was supported by Alfredo (2016) who wrote that the integration is necessary due to the interactions between livestock plant-soil interface and the low selfreliance of the farms. Andriarimalala and Sanderson (2013) argued that integration would allow: (1) reducing the disturbance; (2) improving soil surface; and (3) promoting biological process. This would enable better utilization of resources, improve ecosystem activities, the landscape value and carbon sequestration, eventually improving long-term ecosystem's functionality, as well as its condition, economic behavior and sustainability.

Simulated results show that development of grazing and fodder area improved training and extension services through farmers field schools can boost up beef production in Malaysia. Since beef is an important source of protein and amino acids. Also protein is an important component of daily diet in Malaysia. There is a strong association of food production and consumption (Nesar and Garnett, 2011). Sustainable development of beef production can ensure the availability of more beef and can meet the challenge of increasing demand for beef in Malaysia and hence can enhance food security. Also Larsen and Lilleor (2014) reported strong positive effects of farmer field schools on food security.

\section{Policy Implications}

Beef cattle production in Malaysia is largely dependent on sustainable supply of quality animal feed and Malaysia needs policies for development strategies of beef cattle production for coming years to enhance self-sufficiency in beef and beef products. This study generally suggests the following overall policy implications:

- The results of this study indicate that grazing and fodder area need to be developed to reduce the cost of animal feed

- Training and extension services through farmer field schools should be promoted to develop an accurate ruminant feeding system to improve feed utilization and reduce production cost

- Finally, focus should be given on intensifying research in genetic improvement and enhancing breeding techniques

\section{Conclusion}

Thus far, range of specific strategies has been implemented to improve local beef cattle production issues. In this study a system dynamics analysis has been conducted to simulate and assess the policy options of the beef cattle production. The results of simulation indicate that low beef price and feed cost ratio would worsen beef cattle production. However, development of grazing and fodder area and genetic improvement boost the beef cattle production significantly. The results also indicate that genetic improvement could increase the number of beef cattle drastically at a desired level by 2020 . The simulation results of this research support the idea that the best policies to obtain the targeted self-sufficiency level is through technology adoption (Lobato et al., 2014), importation of animal for breeding, minimized rate of beef cattle mortality, increased fertility and the conduct 
of training in feed efficiency management. This research was undertaken to design a model that can provide better understanding and evaluate the beef cattle production issues. The present study makes several noteworthy contributions for improving decision support to industry participants for understanding the dynamics that are likely to drive beef cattle industry over the next years.

\section{Acknowledgement}

The authors gratefully acknowledge the support by the Ministry of Higher Education (MOHE) for funding this research under the Fundamental Research Grant Scheme (FRGS) at the University of Putra Malaysia.

\section{Author's Contributions}

Ibragimov Abdulla: Contributed to research design, literature review, model development and manuscript preparation and revision.

Fatimah Mohamed Arshad: Contributed to conceptualization, manuscript review and revision and research supervision.

B.K. Bala: Provided technical consultancy about manuscript writing, numerical analyses and discussions.

N.L. Bach: Organized research plan, conducting the analysis and discussion.

Sahra Mohammadi: C ontributed in development of the conceptual framework, carried out the validati on and statistical tests of the developed mode.

\section{Conflicts of Interest}

The author declares no conflict of interest.

\section{References}

Abdulla, I. and F.M. Arshad, 2015. A systems approach to study the Malaysian pepper industry. Am. J. Applied Sci., 12: 487-494.

DOI: 10.3844 /ajassp.2015.487.494

Allen, J. and A. Na-Chiangmai, 2002. Development strategies for genetic evaluation for beef production in developing countries. Proceedings of an International Workshop Held in Khon Kaen Province, Thailand, pp: 108.

Andriarimalala, J.H., J.N. Rakotozandriny, A.L.H. Andriamandroso, E. Penot and K. Naudin et al., 2013. Creating synergies between conservation agriculture and cattle production in crop-livestock farms: A study case in the lake Alaotra region of Madagascar. Experimental Agriculture, 49: 352-365. DOI: $10.1017 / \mathrm{S} 0014479713000112$

Arshad, F.M., B.K. Bala, E.F. Alias and I. Abdulla, 2015. Modelling boom and bust of cocoa production systems in Malaysia. Ecological Modell., 309-310: 22-32. DOI: 10.1016/j.ecolmodel.2015.03.020
Barlas, Y., 1994. Model validation in system dynamics. Int. System Dynam. Conf., 12: 183-210.

DOI: $10.1002 /(\mathrm{SICI}) 1099$ 1727(199623)12:3<183::AID-SDR103>3.0.CO;2-4

Beckett, J.L. and J.W. Oltjen, 1993. Estimation of the water requirement for beef production in the United States. J. Animal Sci., 71: 818-26. DOI: $10.2527 / 1993.714818 x$

Bindon, B.M. and N.M. Jones, 2001. Cattle supply, production systems and markets for Australian beef. Aus. J. Experimental Agriculture, 41: 861-877. DOI: $10.1071 / \mathrm{EA} 01052$

Chiew, F.C., 2001. Globalization and TRADE liberalization implications on livestock industry in Malaysia: Threat or opportunity. Proceedings of the 23rd MSAP Annual Conference, (PAC' 01), pp: 27-29.

Forrester, J.W., 1968. Principles of Systems. Wright Allen Press, Massachusetts, USA.

Hassan, O.A., M. Ishida, I.M.S. and Z.A. Tajuddin, 1994. Oil-palm fronds as a roughage feed source for ruminants in Malaysia oil-palm fronds as a roughage. Proceedings of the Malaysia Agriculture Research and Development Institute (RDI' 94), pp: 1-8.

Hirooka, H., 2010. Systems approaches to beef cattle production systems using modeling and simulation. Animal Science J. Nihon Chikusan Gakkaiho 81: 411-24. DOI: 10.1111/j.1740-0929.2010.00769.x

Ibragimov, A., 2014. Impact of Cpo export duties on Malaysian palm oil industry. Am. J. Applied Sci., 11: 1301-1309. DOI: 10.3844/ajassp.2014.1301.1309

Jamaludin, M.H., M.H. Hassan, M.R. Amin and A.K. Zulhisyam, 2014 .The future of the Malaysian beef industry. J. Tropical Resources Sustainable Sci., 2: 23-29.

Johari, J.A. and Y. Jasmi, 2009. Breeds and breeding program for beef production in Malaysia. Proceedings of the 8th Malaysia Congress on Genetics, Aug. 22-28.

Kusriatmi, R.O., Y. Syaukat and A. Said, 2014. Analysis of the effects of beef import restrictions policy on beef self-sufficiency in Indonesia. J. Int. Society Southeast Asian Agric. Sci., 20: 115-30.

Larsen, A.F. and H.B. Lilleør, 2014. Beyond beyond the field: The impact of farmer field schools on food security and poverty alleviation. World Development, 64: 843-859. DOI: $10.1016 /$ j.worlddev.2014.07.003

Lobato, J.F.P., A.K. Freitas, T. Devincenzi, L.L. Cardoso and J.U. Tarouco et al., 2014. Brazilian beef produced on pastures: Sustainable and healthy. Meat Science, 98: 336-45.

DOI: 10.1016/j.meatsci.2014.06.022 
Loh, T.C., 2002. Livestock production and the feed industry in Malaysia. Animal Science, Malaysia.

Martha, G.B., E. Alves and E. Contini, 2012. Landsaving approaches and beef production growth in Brazil. Agric. Systems, 110: 173-77. DOI: 10.1016/j.agsy.2012.03.001

Meadows, D.H., 1979. The Unavoidable a Priori. In: Elements of the System Dynamics Method, J. Randers (Ed.)., MIT Press, Cambridge MA.

Mohamed, Z., A. Hosseini and N.H. Kamarulzaman. 2013. Analysis of Malaysian beef industry in peninsular Malaysia under different importation policies scenarios and rate management systems. Pertanika J. Social Sciences Humanities 21: 1-16.

Mohamed, Z.A., 2007. The Livestock Industry. 50 years of Malaysian agriculture: Transformational issues, challenges and direction. Penerbit UPM, Serdang.

Morris, S.T. and P.R. Kenyon, 2014. Intensive sheep and beef production from pasture--a New Zealand perspective of concerns, opportunities and challenges. Meat Science, 98: 330-35.

DOI: 10.1016/j.meatsci.2014.06.011
Nesar, A. and S.T. Garnett, 2011. Integrated rice-fish farming in Bangladesh: meeting the challenges of food security. Food Security, 3: 81-92.

Rosen, S., K.M. Murphy and J.A. Scheinkman, 1994. Cattle cycles. J. Political Economy, 102: 468-468. DOI: $10.1086 / 261942$

Sanderson, M.A., D. Archer, J. Hendrickson, S. Kronberg and M. Liebig et al., 2013. Outcomes from pastures and integrated crop-livestock systems. Renewable Agricultural Food Systems, 28: 129-144.

Schultz, T., 1974. Transforming traditional agriculture. University of Chicago Press.

Slade, E.M., M.I. Burhanuddin, J. Caliman, W.A. Foster and M. Naim et al., 2014. Can cattle grazing in mature oil palm increase biodiversity and ecosystem service provision.

Sterman, J., 2000. Business Dynamics: Systems Thinking and Modeling for a Complex. McGrawHill/Irwin; 1 Edition.

Tohiran, K.A., S. Ismail, R.Z. Raja Omar, W. Omar and Z. Abdullah, 2008. Integration of Yellow Cattle in oil Palm. MPOB Information Series. 